\title{
Development and evaluation of an interactive online education platform to facilitate dietary change in pediatric inflammatory bowel disease
}

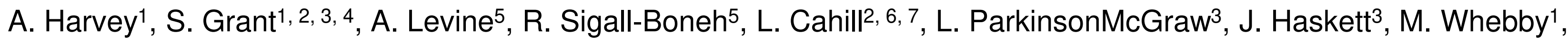

J. Van Limbergen², 3

${ }^{1}$ Mount Saint Vincent University, Halifax, NS, ${ }^{2}$ Dalhousie University, Halifax, NS, ${ }^{3}$ Izaak Walton Killam Health Centre, Halifax, NS, ${ }^{4}$ York University, Toronto, ON, ${ }^{5}$ Wolfson Medical Centre, Holon, Israel, ${ }^{6}$ Queen Elizabeth II Health Sciences Centre, Halifax, NS, ${ }^{7}$ Harvard T. H. Chan School of Public Health, Boston, MA

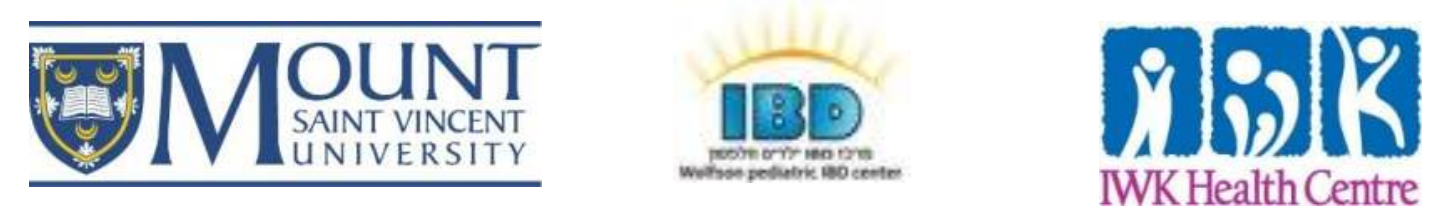

INTRODUCTION

The effectiveness of the Crohn's Disease Exclusion Diet (CDED) as a treatment for Pediatric Crohn's Disease (PCD) is currently being investigated. Feedback from previous $(n=47)$ and current $(\mathrm{n}=78)$ use of the CDED in an Israeli sample indicated additional support was needed during the intervention [1,2]. This feedback is supported by the literature, as lack of support, misinformation about the therapeutic diet, and need for reliable education materials have been cited as common barriers to dietary intervention implementation [3-10]. The Canadian CDED Study (CDED-CA) provided an opportunity to address CDED feedback, tailor the education-based intervention to the Canadian sample, and embed education evaluation into the CDED-CA.

\section{OBJECTIVES}

To develop and evaluate a client-centred education platform for use in dietary intervention implementation in PCD.

\section{METHODS}

Sample: Participants (aged 4 to 18 years; $n=7$ ) were recruited from the intervention group at one of the CDED-CA sites. Theoretical Framework for Education Evaluation: The Kirkpatrick Model of Effective Education Evaluation (KM) informed the development of the CDED Questionnaire (CDED-Q). KM has been used in healthcare settings to evaluate education-based interventions [9,11,12]. The KM uses four levels to evaluate interventions: 1) reaction (satisfaction); 2) learning (knowledge uptake); 3) behaviour (knowledge transfer); and 4) results (targeted health outcomes) [13].

Education Intervention Development and Evaluation: Existing CDED nutrition education materials were adapted and additional education materials were created, including an online platform (website) which housed all patient education materials (PEMs). The intervention was 12 weeks and included in-person sessions (Week 0 and 6) and the website. The first three levels of the KM were assessed using the CDED-Q (which contained four sections); three-day diet records were also used to assess KM Level 3 (Table 1). Level 4 of the KM was not assessed, as it is being evaluated by the CDED Study (main randomized controlled trial). Ethics approval was received from the Mount Saint Vincent University and IWK Health Centre Research Ethics Boards.

Table 1. Data Collection by CDED Study Week

\begin{tabular}{|l|c|c|c|c|c|c|}
\hline \multirow{2}{*}{$\begin{array}{l}\text { Data Collection } \\
\text { Tool }\end{array}$} & $\begin{array}{c}\text { Week 0 } \\
\text { (clinic) }\end{array}$ & $\begin{array}{c}\text { Week 1 } \\
\text { (phone) }\end{array}$ & $\begin{array}{c}\text { Week 3 } \\
\text { (clinic) }\end{array}$ & $\begin{array}{c}\text { Week 6 } \\
\text { (clinic) }\end{array}$ & $\begin{array}{c}\text { Week 9 } \\
\text { (phone) }\end{array}$ & $\begin{array}{c}\text { Week 12 } \\
\text { (clinic) }\end{array}$ \\
\cline { 2 - 7 } \\
\hline $\begin{array}{l}\text { CDED-Q Section 1 } \\
\text { (Reaction) }\end{array}$ & & $\mathrm{X}$ & & & $\mathrm{X}$ & \\
\hline $\begin{array}{l}\text { CDED-Q Section 2 } \\
\text { (Demographics) }\end{array}$ & $\mathrm{X}$ & & & & & \\
\hline $\begin{array}{l}\text { CDED-Q Section 3 } \\
\text { (Learning) }\end{array}$ & $\mathrm{X}$ & $\mathrm{X}$ & & $\mathrm{X}$ & $\mathrm{X}$ & \\
\hline $\begin{array}{l}\text { CDED-Q Section 4a } \\
\text { (Behaviour) }\end{array}$ & & & & $\mathrm{X}$ & $\mathrm{X}$ & $\mathrm{X}$ \\
\hline $\begin{array}{l}\text { Three-day Diet } \\
\text { Record (Behaviour) }\end{array}$ & $\mathrm{X}$ & & $\mathrm{X}$ & $\mathrm{X}$ & $\mathrm{X}$ & $\mathrm{X}$ \\
\hline
\end{tabular}

CDED = Crohn's Disease Exclusion Diet; CDED-Q = CDED Questionnaire

\section{DALHOUSIE UNIVERSITY}

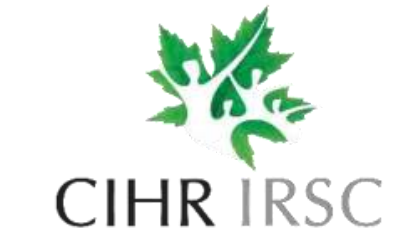

\section{RESULTS}

Five participants were enrolled in the study; one was lost to follow-up at Week 6 due to treatment failure in the CDED-CA. The CDED-Q completion rates varied by week and were between $50 \%(2 / 4)$ and $100 \%(5 / 5 ; 4 / 4)$. All Likert-scale satisfaction question responses were positive ("strongly agree" or "agree") except one. Mean knowledge scores increased significantly from pre-education (Week 0) to Week 1, Week 6, and Week 9 (Table 2, Table 3). All participants (except one in Week 6 ) indicated that $76 \%$ to $100 \%$ of total food intake was CDED foods; the diet records confirmed reported compliance.

Table 2. CDED-Q Section 3 (Knowledge) Score Results



CDED = Crohn's Disease Exclusion Diet Questionnaire; SD = standard deviation; * $p<0.05$

\section{CONCLUSION}

The results suggest that a tailored, online education platform may be an effective strategy for dietary intervention implementation in the PCD population.

\section{RELEVANCE TO PRACTICE}

The education framework could assist with future CDED implementation and evaluation. Currently, the PEMs are being used on the Nestle Health Science ModuLife ${ }^{\mathrm{TM}}$ website, which provides CDED support to patients and health care providers internationally [14].

References: [1] Sigall-Boneh et al. 2014;20:1353 1360.; [2] Van Limbergen et al. J Crohns Colitis. 2019;13(Suppl1):S003.; [3] Bacigalupe \& Plocha. Fam Syst Health. 2015;33(1):46-54.; [4] Bernstein et al. J Hum Nutr Diet. 2014;27(Suppl2);4-11.; [5] Burrowes et al. J Ren Nutr. 2005;15(4):407-26.; [6] Trudel et al. J Ren Nutr. 2010;20(4):235-42.; [7] Roma et al. J Hum Nutr Diet. 2010;23(2):176-82.; [8] Grant \& Wolever. Nutrients. 2011;3(3):330-40.; [9] Grant et al. Poster session presented at Diabetes Canada/CSEM Profession Conference. 2016.; [10] MacCulloch \& Rashid. Paediatr Child Health. 2014;19(6):305-9.; [11] Grant et al. Diabetes Res Clin Pract. 2011;91(1):1522.; [12] Pehrson et al. BJOG. 2011;118(8):926-35.; [13] Kirkpatrick Partners: The One and Only Kirkpatrick [Internet]. 2009-2019.; [14] Nestle Health Science ModuLife ${ }^{T M}$ [Internet]. 2019. 